\title{
Experiences at the Academy of Fine Arts of Brera in Milan, Italy: the application of laser-technology on three case studies of the historical heritage
}

\author{
Elisa Isella ${ }^{1 \star}$, Donatella Bonelli ${ }^{1}$, Silvia Cerea ${ }^{1}$, Francesca Mancini ${ }^{1}$, Veronica \\ Ruppen ${ }^{1}$, Alessandra Botteon ${ }^{2}$, Antonio Sansonetti ${ }^{2}$ \\ 1 Brera Fine Arts Academy, Milan, Italy - Via Brera 28, 20121, Milan \\ 2 Institute for Conservation and Valorization of Cultural Heritage ICVBC - CNR, Milan, Italy - Via \\ Roberto Cozzi, 53, 20125 Milan \\ * Corresponding author: elisa.isella@libero.it
}

\begin{abstract}
Scientific research regarding the conservation of gypsum plaster heritage is quite scarce; cleaning is often a problematic issue on this kind of material due to its water sensitivity and mechanical features. Therefore, laser cleaning is often a good option as some recent paper has reported.

The research presented here focused on laser cleaning on three gypsum plaster casts belonging to the collection of Brera Fine Arts Academy and dated back to the $19^{\text {th }}$ century; recalling the names of the original marble statues, the items are the Flora Farnese, The Velletri Pallas and the Barberini Faun. The three casts had been exposed for many decades in the entrance hall of the Academy in a semi-confined environment. Unfortunately, the continuous passage of students soiled the plaster surface with a grey greasy layer localized especially on the lower parts and on the surfaces with a strong horizontal component. It was possible to identify a superficial grime and traces of the original patina. Marks of different nature (felt, pen, pencil, scratches) were also present. Cleaning tests were carried out using Thunder Art Nd:YAG able to emit both at $1064 \mathrm{~nm}$ and at $532 \mathrm{~nm}$. The effects of laser cleaning were studied with a diagnostic campaign carried out both before and after the cleaning operation. To define the aspects and the nature of the surface microsamples were sampled and analysed with XRD, XRF, then observed with a scanning electron microscope SEM, and with optical microscopy.

Several tests were carried out on the Flora Farnese, calibrating the fluence in order to match the ablation threshold avoiding any damage (from $\mathrm{FL}=1-1,45 \mathrm{~J} / \mathrm{cm}^{2}$ at $1064 \mathrm{~nm}$ to $\mathrm{FL}=0,5-0,7 \mathrm{~J} / \mathrm{cm}^{2}$ at $532 \mathrm{~nm}$ with repetition rate from $6 \mathrm{~Hz}$ to $10 \mathrm{~Hz}$ ) in particular on these surfaces the removal of cement splashes constituted a hard task. A comparison in between tests at $1064 \mathrm{~nm}$ and at $532 \mathrm{~nm}$ were performed. Both tests were evaluated with the aid of humidification with free water (applied with brush) and with the use of AgarArt ${ }^{\oplus}$ rigid gel. On the basis of laser-plaster interaction observed on the Flora, the tests on the other casts excluded the IR radiation, because of a yellowing effect. For what regards the cast of the Pallas, one of the low relieves in the wooden support base was involved. The laser cleaning allowed the perfect removal of the outer layers of scialbo.

For the cast of the Faun, laser cleaning proved to be the appropriate system to eliminate greasy deposits and dark grey stains visible on the irregular surface, maintaining the original morphology. Hence it was possible to avoid invasive mechanical and chemical systems, minimizing the interaction with the matter and saving working time. The aim of this work is to provide a contribution to the scientific
\end{abstract}


researches by the point of view of a Fine Arts Academy, which is starting to build a database for the conservation products and methods about such a known and used material as plaster, which is not sufficiently studied.

Keywords: Nd:YAG, $532 \mathrm{~nm}$ radiation, plaster casts, guano, Newberyite, ablation threshold, safety and security

\section{Introduction}

Cleaning artwork mainly composed by gypsum is a hard challenge even for skilled conservators. Gypsum is partly soluble and moreover, it is very sensitive to any kind of wet cleaning; furthermore, it is not mechanically resistant to abrasive systems and its resistance is dramatically decreased even when it is slightly wet. However, the interaction between the cleaning system and the gypsum surface is influenced by secondary components, especially when there are organic additives such as animal glues or other protein materials. Recently the Agar cleaning has proved to be efficacious on this kind of artworks, even though some research is still needed in this field. Laser cleaning allows to remove soiling, but at the same time avoiding damages to the artwork as proved by some recent papers [1].

This research focuses on the application of laser cleaning on three gypsum plaster casts of the historic collection of the Fine Arts Academy of Brera, dating back to the $19^{\text {th }}$ century; they are the Flora Farnese, the Velletri Pallas and the Barberini Faun. Laser cleaning was applied to remove the compact grayish deposits present on the surface and partially penetrated into the gypsum. The Nd:YAG laser source was chosen for the advantages offered by its versatility and broad operating range of laser pulse durations. This instrument was employed to complete a predominately mechanical ablative process with the emission of short impulses in Q-switch to avoid the excessive heating of the surface usually associated with long pulse duration. Furthermore, based on the research of basic laser interaction mechanisms, recent bibliographic references $[2,3]$ have suggested to operate in the visible spectrum at $\lambda=532$ $\mathrm{nm}$ to avoid the undesirable yellowing of the substrate.

\section{The Brera Academy of Fine Arts}

The survey here presented was carried out at the Conservation School in the Academy of Fine Arts, an Italian Institute that is based in Milan and was founded in 1776 by Empress Maria Teresa of Austria. The Brera building hosts various institutional bodies such as the Ministry of Culture, the Fine Art Gallery, the Botanical Garden, the Astronomical Observatory and the Braidense Library; they are all enclosed together to create a network. The overall collection is worldwide renowned. It goes back to the $19^{\text {th }}$ century and consists in different kinds of works like paintings, ancient books, drawings, sculptures and plaster casts. The Conservation School was founded in 1997.The Historical Heritage of Brera Academy is composed by 900 gypsum plaster casts positioned in several of school spaces, both public and reserved to the students. All the conservation activities are devoted at the aim to create the new gypsum gallery in the original old basement of the Academy. The Heritage Collection could 


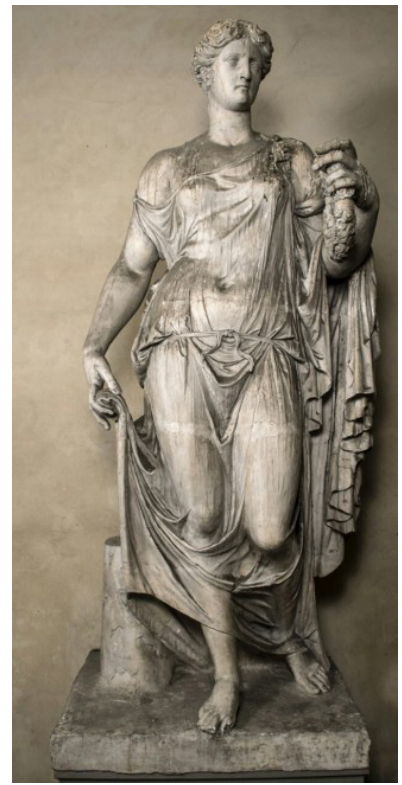

Fig. 1. Flora Farnese before the restoration.

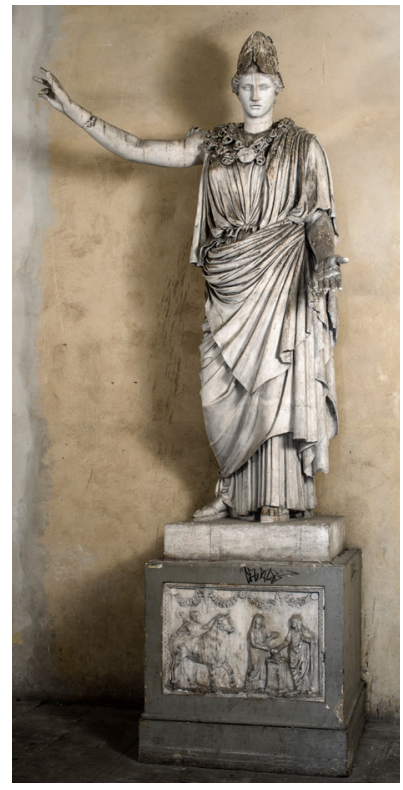

Fig. 2. Velletri Pallas before the restoration.

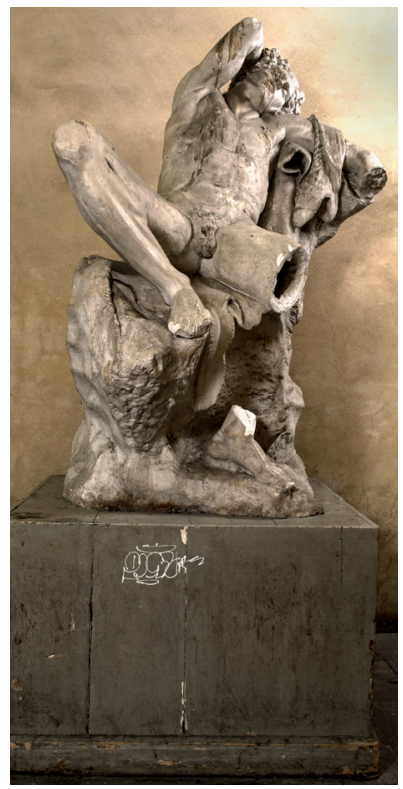

Fig. 3. Barberini Faun before the restoration. be split into two parts: the $19^{\text {th }}$ and the $20^{\text {th }}$ century artworks, different for size, materials and techniques.

The oldest artwork category group includes items of huge dimensions, which were modelled by using the original marbles; on the contrary, the recent heritage is mainly formed by prototypes useful to the artist for the final marble sculpture.

\section{The case studies}

The Flora Farnese, Velletri Pallas and Barberini Faun (Figs. 1-3) are three gypsum plaster casts dating back to the end of the $18^{\text {th }}$ century: their sizes constitute a challenge for the conservators, being in the range from $2,04 \mathrm{~m}$ to $3,55 \mathrm{~m}$ approximately. They were made from original marble statues which are currently conserved in three different museums: the Archaeological Museum of Naples (Flora Farnese), the Louvre Museum (Pallas of Velletri) and the Munich Glyptothek (Barberini Faun).

These three sculptures were located for the last decades in the entrance hall of the Academy, in a large hallway leading to the Academy classrooms. This semi-confined environment favours the ventilation and acts on the average of the temperature and the relative humidity, which replicates seasonal standards. Urban colonies of pigeons and the constant flow of visitors and students in the corridors created different processes and patterns of decay.

Plaster casts surfaces were covered by a thick layer of different exogenic material, composed of pigeon dropping (guano) (Fig. 4), solid particles coming both from soil and pollution. As a result of the contact with human hands, a greasy, grey layer had 


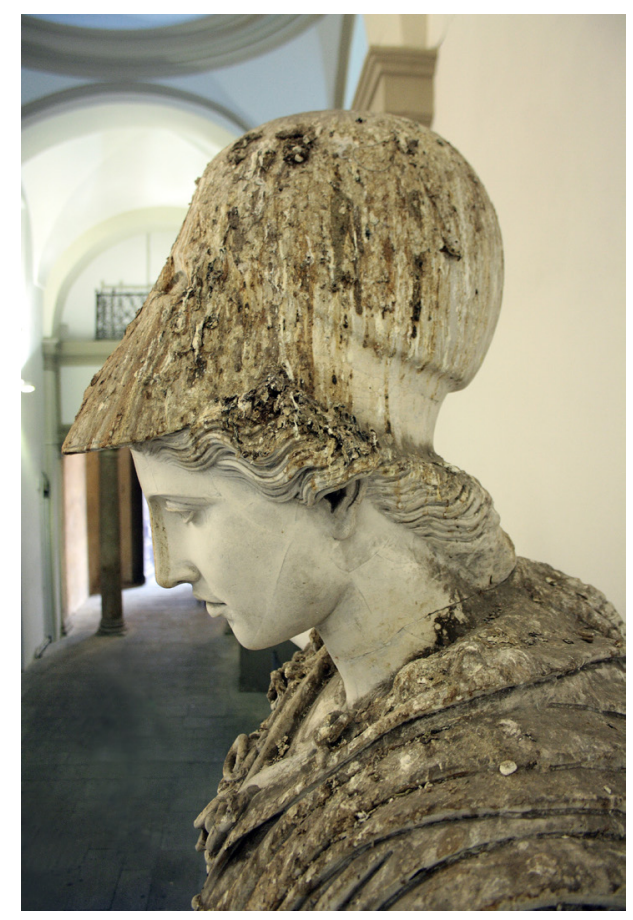

Fig. 4. The Velletri Pallas helmet covered with a thick and uneven layer of guano.

been formed on the lower part of the plaster casts; moreover, the artworks were damaged by different acts of vandalism, which caused the fracture of exposed extremities. The most

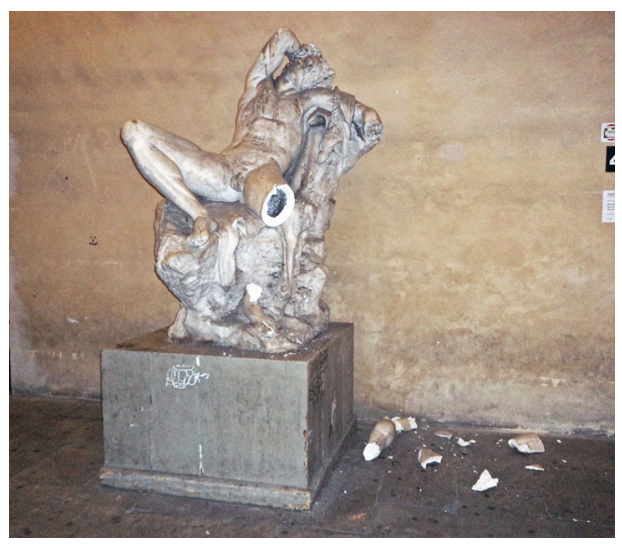

Fig. 5. Barberini Faun with fragments of the left leg after the vandalism act. recent act of vandalism was inflicted on the Barberini Faun in March 2014: the left leg was detached due to an inappropriate move caused by a student (Fig. 5), whereas the Pallas was intentionally splattered with blue paint (Fig. 6).

Previous restoration and masonry building maintenance severely worsened the state of the conservation of the three sculptures; especially the surface of Flora which was damaged by splashes of a grey mortar. An in-depth study of the composition of the gypsum plaster matrix highlighted interesting details about the execution of the three casts; specific technical diagnostic methods were used leading to the current phase of conservation.

Through X-ray diffraction (XRD) and thermal analysis (TGA-DTA), it was possible to identify gypsum as the principal component, with a presence up to $90 \%$; the rest is composed of traces of bassanite, quartz and calcium oxalates. There is also a minimum percentage of organic substances, specifically traces of protein highlighted by infrared

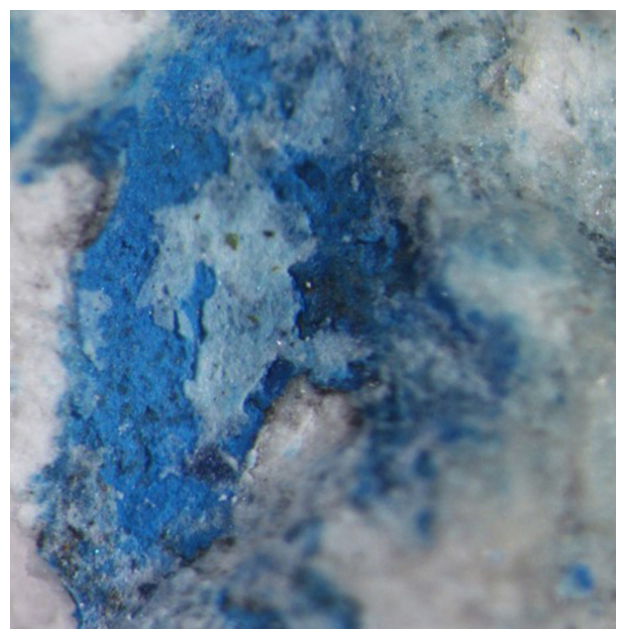

Fig. 6. The vandalism act on the Pallas surface: a detail of the blue stain splattered, observed at the stereomicroscope. 

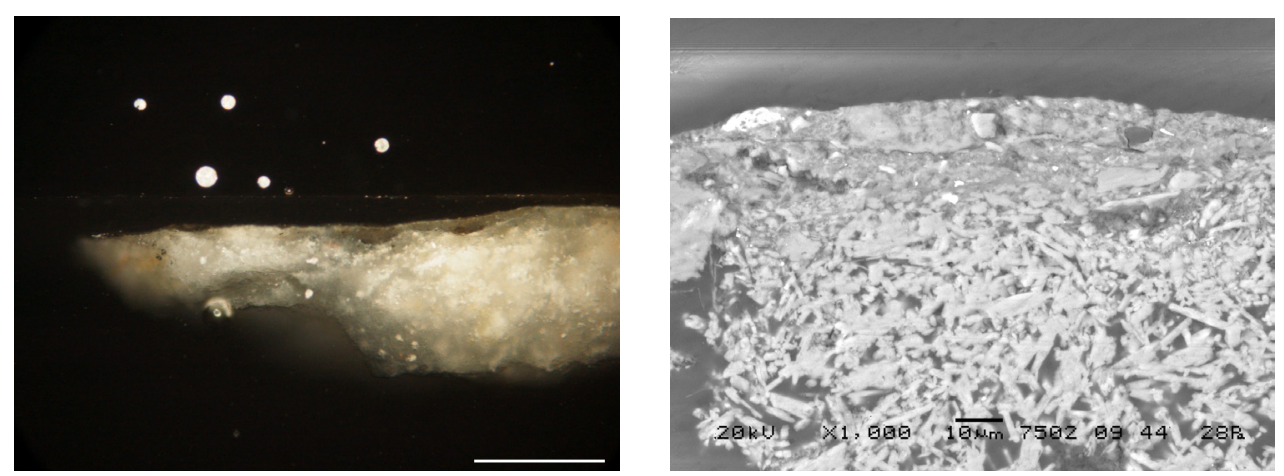

Figs. 7 and 8. Optical and SEM images in backscattered electrons of the uncleaned area. They show the stratigraphic sequence of the plaster.

spectroscopy (FTIR). The optical and the scanning electron microscope (SEM) images (Figs. 7 and 8) provided the stratigraphic sequence of the plaster surface.

On the outer gypsum surface it was possible to observe a grey layer that at the naked eye appeared to be a scialbo. However, this hypothesis could not be confirmed by further analysis; in fact, no specific distinctive layer was present, but phosphorus, magnesium and silicon have been detected by EDS spectra on the surface and the near/surface region of the
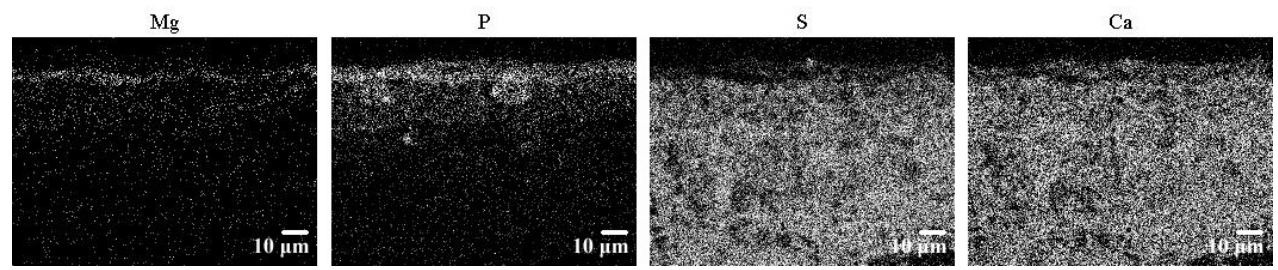

Fig. 9. SEM - EDS maps of magnesium, phosphorus, silicon and calcium.

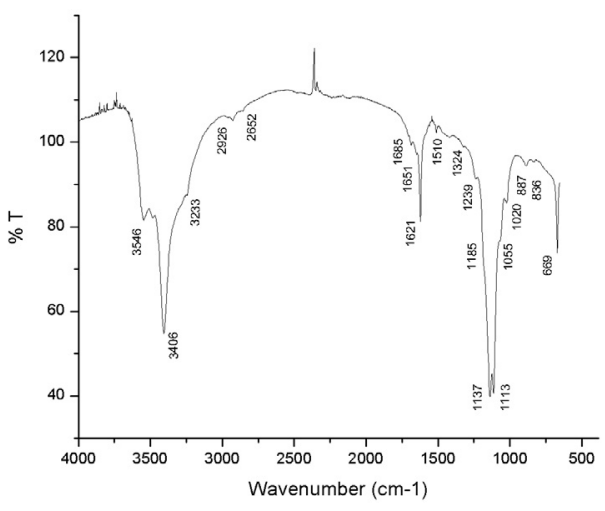

Fig. 10. FITR spectrum of Newberyite after irradiation. gypsum matrix. It is possible to see tracks of these elements in the maps (Fig. 9).

FTIR spectrum (Fig. 10) shows the absorption pattern of unknown material sampled from the grey layer. It displays a good overlapping referring to the mineral Newberyte. This is a magnesium hydrogen phosphate which crystallizes with three molecules of water $\left[\mathrm{Mg}\left(\mathrm{HPO}_{4}\right) \cdot 3 \mathrm{H}_{2} \mathrm{O}\right]$. The hydrogen phosphate ion is reported to be prevalent in weakly basic conditions, but it is still present in a significant amount at $\mathrm{pH}$ 7 [4]. Different forms of magnesium phosphates have been detected as crystalline forms 
in animal's guano. Depending on the guano age, the presence of humidity, the content of ammonium ion, a different mineral phase is formed: Struvite $\left[\mathrm{MgNH}_{4} \mathrm{PO}_{4} \cdot 6 \mathrm{H}_{2} \mathrm{O}\right]$, occurs in fact in great abundance in the moist depth of guano, while on the contrary, Newberyte occurs in the older and drier parts of the deposits. Its colour is described as greyish or grey/brown [5]. As a general rule, the hydrogen and di-hydrogen phosphates are slightly more soluble than the corresponding phosphates [6]. The low solubility product of newberyte $1,510^{-6}$ at $25^{\circ} \mathrm{C}$ (Taylor, 1963), compared to the $\mathrm{K}_{\mathrm{sp}}$ of gypsum, $10^{-4.58}$ allows to suppose that the mechanism explains the current localization of phosphate and magnesium in the near-surface region [7]. Subsequent cycles of condensation phenomena, solubilize a greater amount of gypsum in the outer surface, leaving the Newberyite intact; the following re-precipitation of gypsum in a drier season, moves it forward to the outer profile of the surface. Newberyite has been detected in cave minerals, in guano and in kidney stones. In the field of cultural heritage, the scientific literature reported an occurrence of this substance on ivory surfaces [8]. In this paper, the first detection on gypsum statues was presented, as to the authors knowledge.

\section{Previous treatments and preliminary laser test}

The conservation works began in October 2014. The preliminary cleaning phases were the following:

1. Dry cleaning (Fig. 24)

2. Wet cleaning (Fig. 11)

3. Agar Gel cleaning (Fig. 11 and Fig. 25)

Processing with a dry cleaning on a decayed gypsum surface, using a synthetic rubber or a sponge, kneads the soiling onto the gypsum matrix. This is a drawback, because it produces an uneven cleaning level, which gives the impression of a stained surface. Wetting the surface with a water based system and adding water to the gypsum material with a brush or a poultice did not help at all; on the contrary, it enhanced the possibility of permanent damages.

The Agar gel was not effective inside the scratches and the poultice seemed to damage the morphology of the plaster surface (Fig. 11).

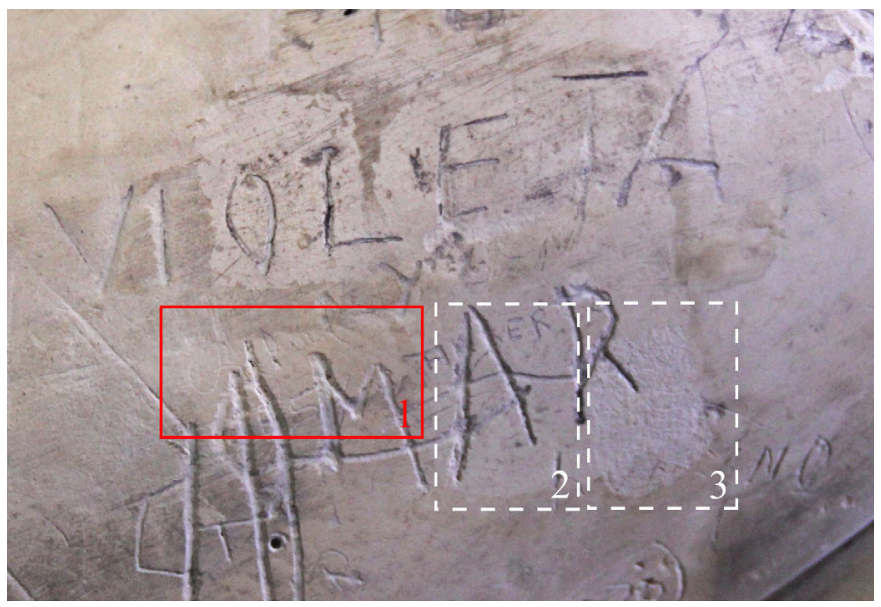

Fig. 11. Laser test (1) gel test (2) solvent pad test (3). 


\section{The laser cleaning}

Eventually, laser cleaning tests were performed (Figs. 12-13). As already mentioned, with gels and poultice solvent (hydro-alcoholic solution) the cleaning resulted in an unsatisfactory surface respect to the laser, which on the contrary, proved a correct balance between harmfulness and effectiveness.

Several laser tests (THUNDER ART - El. En. - Florence, Italy) were carried out on the Flora Farnese, calibrating the fluence (FL) in order to match the ablation threshold avoiding damages from $\mathrm{FL}=1 \div 1,45 \mathrm{~J} / \mathrm{cm}^{2}$ at $1064 \mathrm{~nm}$ to $\mathrm{FL}=0,5 \div 0,7 \mathrm{~J} / \mathrm{cm}^{2}$ at 532 $\mathrm{nm}$ with repetition rates within the range 6 $\mathrm{Hz}$ to $10 \mathrm{~Hz}$. A comparison in between tests was performed at $1064 \mathrm{~nm}$ and at $532 \mathrm{~nm}$. Both tests were evaluated with some support like wetting with clear water (applied with

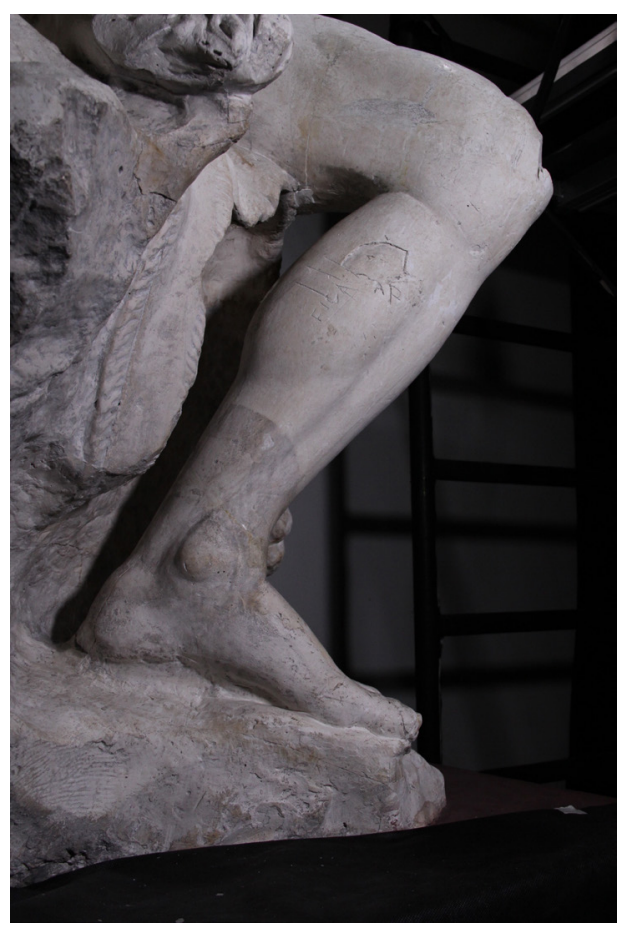

Fig. 12. Laser test at $1.5 \mathrm{~J} / \mathrm{cm}^{2}$. a brush) and using the AgarArt ${ }^{\circ}$ rigid gel as an intermediary agent. A yellowing effect was observed on the Flora surfaces, which led to the exclusion of the radiation $1064 \mathrm{~nm}$, on the other two casts.

As it is possible to see in the maps of the elements, the ablation at FL over $1.9 \mathrm{~J} / \mathrm{cm}^{2}$ removed almost completely the magnesium and phosphorus formations, clearly indicating an overcleaning (Fig. 17). The visual results displayed in Fig. 15 highlighted in fact an unnatural white surface, where a portion of the near-surface region has been removed with the outcome that it damaged the surface of the gypsum work (Figs. 14-17).

In conclusion, analyses were carried out to evaluate the differences between the untreated and cleaned laser zones; they allowed to observe the partial lowering of the Newberyte formation avoiding its com-

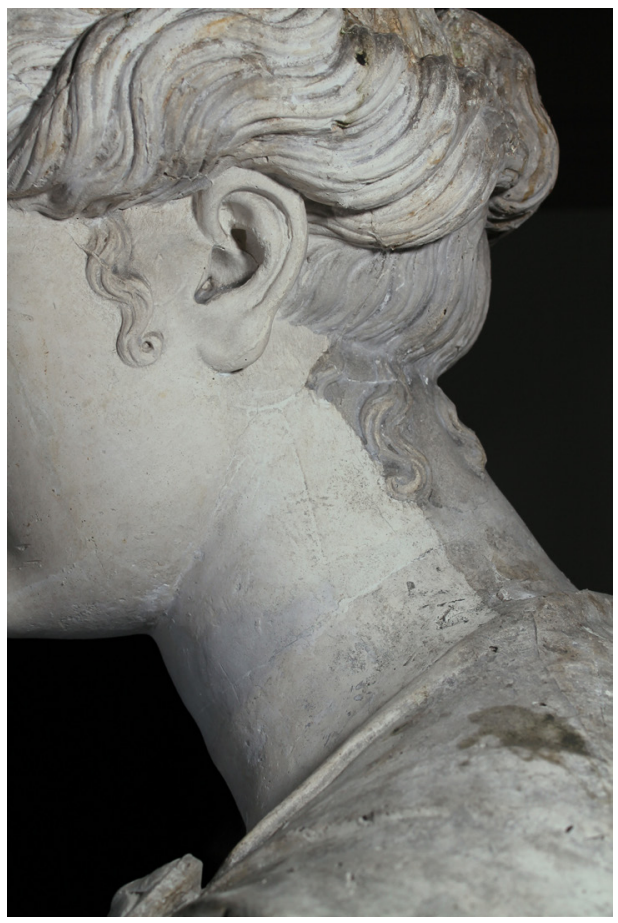

Fig. 13. Laser test at $0.7 \mathrm{~J} / \mathrm{cm}^{2}$. 
plete removal, except for the over cleaning case.

In order to remove the grey layer, which covered a wide range of the surface, it was decided to complete the cleaning with the laser THUNDER ART (El. En. - Florence, Italy; wavelength $=532 \mathrm{~nm}$; spot size $10 \mathrm{~mm}$; pulse duration $\approx 8$ ns. (Fig. 26).

Working with the THUNDER ART Laser allowed the completion of the complex phase

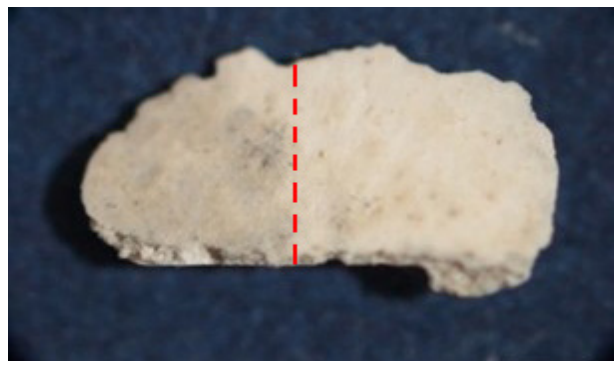

Fig. 14. The sample before and after a cleaning test (the grey layer has become thinner).

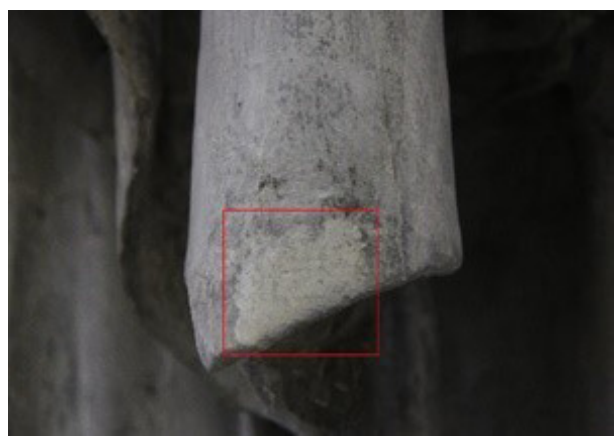

Fig. 15. The laser removal shows an overcleaning level.

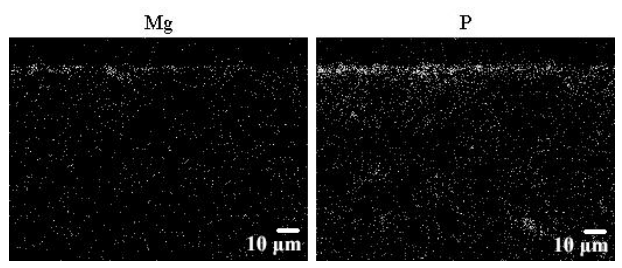

Fig. 16. Ablation threshold. These maps show that the Newberyite has decreased after the laser cleaning. of cleaning by optimizing working time, but also achieving better results compared to the traditional cleaning methods previously tested. Thanks to its high selectivity, the laser system allowed full control and respect of the surface characteristics. Moreover, the laser beam offered the possibility to clean the undercut areas such as the internal folds of clothing, the flowers garland, and other particularly delicate surfaces like the carnation. The cleaning operations on the three plaster casts necessitated approximately fifteen working days.

As a first step, the lower parts of the casts were irradiated, specifically the bases made of plaster because of their easy access. The plaster bases of the Pallas and the Flora have a smooth and simple morphology and it was possible to reach an excellent level of cleaning by using a fluence $=1.7 \mathrm{~J} / \mathrm{cm}^{2}$. Regarding the Faun, it was necessary to use a range of fluence from 1 to $1.7 \mathrm{~J} / \mathrm{cm}^{2}$ (higher with respect to preliminary the tests) because the plaster base had an irregular rocky surface, which carries the working marks, transferred on the plaster from the original marble. During this first laser tests, it was obligatory to take into consideration the cleaning of the bas-relief located in the front of the wooden base structure on which the plaster cast of the Pallas stands (Figs. 18-19). Fluence $=0.7 \mathrm{~J} / \mathrm{cm}^{2}$ was used to remove the homogenos grey layer of the background, while the figures were treated with fluence $=$

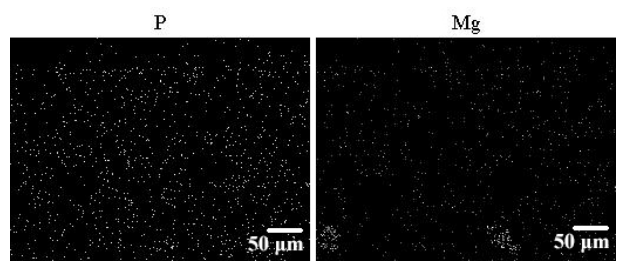

Fig. 17. Overcleaning. These maps show that the Newberyite is no longer present. 


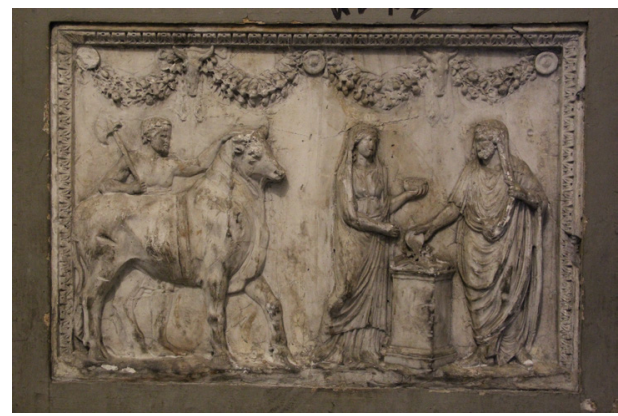

Fig. 18. Low relief before irradiation.

$0.8 \mathrm{~J} / \mathrm{cm}^{2}$, also increasing the value on stains up to a maximum of $1 \mathrm{~J} / \mathrm{cm}^{2}$. It was necessary to modulate the values of fluence and the repetition frequency, instead of using fixed parameters, to be able to clean effectively the draped dresses of the two female figures.

To clean the tunic of the Pallas which is folded on the hips forming a large draping triangle, it was needed to use a range of fluence that varied from $1 \mathrm{~J} / \mathrm{cm}^{2}$, to $1.4 \mathrm{~J} /$ $\mathrm{cm}^{2}$, and a repetition frequency of $12 \mathrm{~Hz}$.

Laser cleaning proved to be particularly effective to eliminate the accumulated black particles in the areas underneath the vertical folds and under the laying zones of the richly decorative elements of the breastplate (depicting snakes and the head of Medusa) (Figs. 20-21).

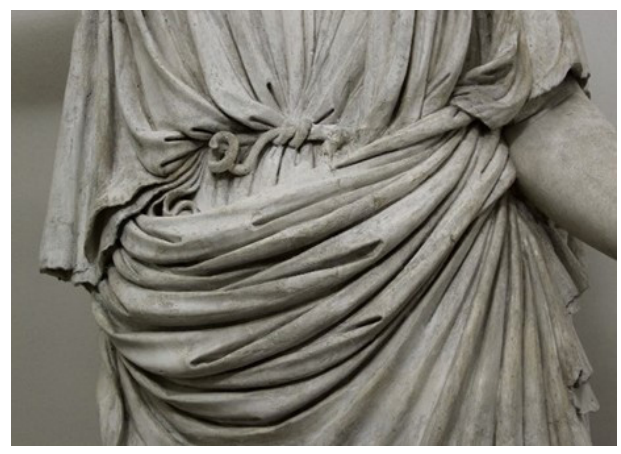

Fig. 20. The tunic of the Pallas before laser treatment.

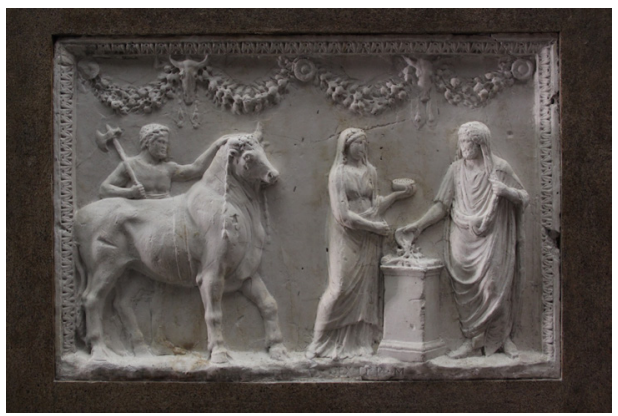

Fig. 19. Low relief after irradiation at $0.7 \mathrm{~J} / \mathrm{cm}^{2}$.

The technical difficulty in these two cases was keeping the hand tool as perpendicular as possible to the modelled surface; on the contrary, extra care had to be taken of the Flora plaster cast in order to be able to execute a uniform cleaning, respecting the chiaroscuro effects, which give plasticity to the figure. Her left forearm holds the elegant draping of the himation (a type of clothing); this area was irradiated with values of fluence from $0.9 \mathrm{~J} / \mathrm{cm}^{2}$ to $1.4 \mathrm{~J} / \mathrm{cm}^{2}$ at a repetition frequency of $18 \mathrm{~Hz}$ (Figs. 22-23). Excellent results were achieved on the wreath of flowers, where blackened areas were successfully removed in the spaces among the flowers.

In correspondence with the anatomical parts, it was necessary to be very careful and delicate and to use the right manual skills. In

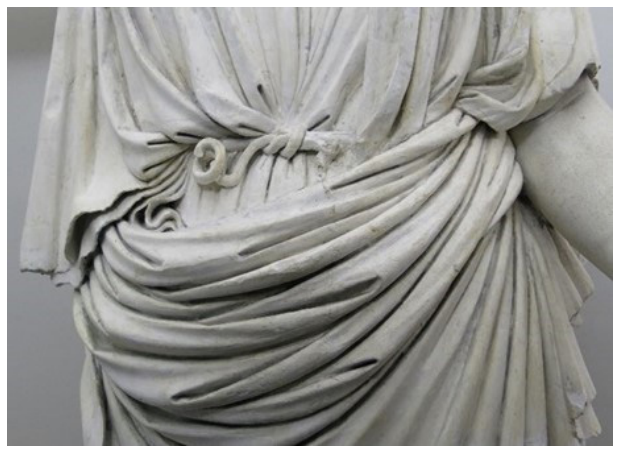

Fig. 21. The tunic of the Pallas after laser treatment. 


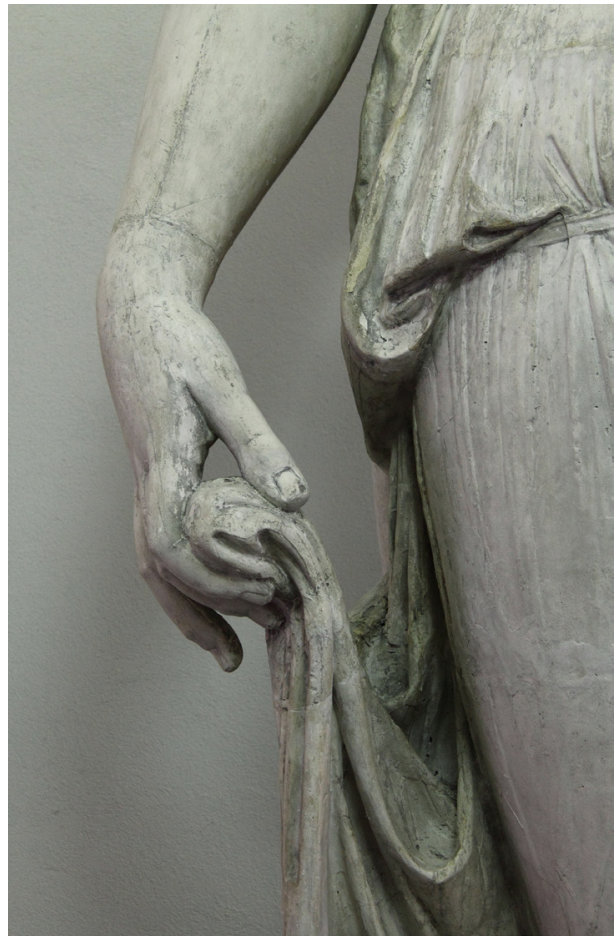

Fig. 22. Particular of the hand before laser cleaning.

particular, the nudity of the Faun regained the full lapse definition of details, which previously were hidden by deposits irregularly distributed on the modelled surface.

The expression on his face and the natural rendering of the abdominal band re-emerged using the laser with a range of fluence starting with $0.7 \mathrm{~J} / \mathrm{cm}^{2}$ through $1.5 \mathrm{~J} / \mathrm{cm}^{2}$, with a repetition frequency of $7 \mathrm{~Hz}$ (Fig. 26). To remove the grey layer, which was easily evident on the faces of the other two casts, the laser parameters varied its distance from the hand tool to the modelled surface. The values in the interval between $0.5 \mathrm{~J} / \mathrm{cm}^{2}$ and $1.1 \mathrm{~J} / \mathrm{cm}^{2}$ were used to obtain a modulated cleaning based on the state of the conservation of different surfaces.

The left leg of the Faun is considered as a "special issue" because of the obvious

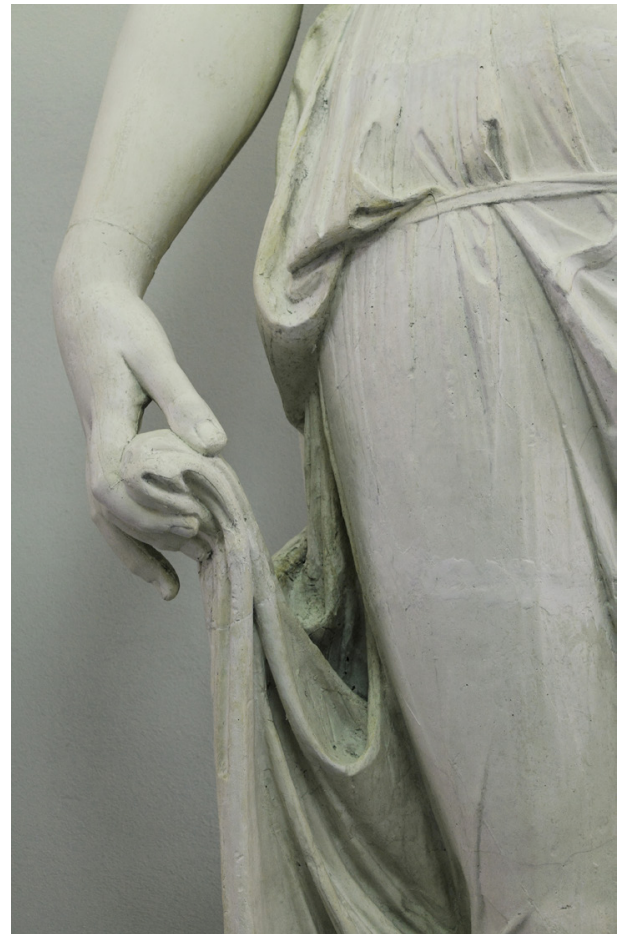

Fig. 23. Particular of the hand after laser cleaning.

signs of deposits due to the interaction with the environment, the plaster material and the problems related to its previous recent reconstruction. The signs of the deposits were removed with fluence from $1 \mathrm{~J} / \mathrm{cm}^{2}$ to 1.7 $\mathrm{J} / \mathrm{cm}^{2}$, while the marks in correspondence of the integration filling stucco needed to be increased up to the high value of $3 \mathrm{~J} / \mathrm{cm}^{2}$.

In the previously mentioned target areas, produced by the first laser tests, a blackening was observed due to a focused laser irradiation; continuing the irradiation in the same points with increased fluence $\left(1.7 \mathrm{~J} / \mathrm{cm}^{2}\right.$ to $3 \mathrm{~J} / \mathrm{cm}^{2}$ ) allowed removing the blackening. This phenomenon was possibly provoked by the presence of an acrylic resin, binding a pigment and previously applied to uniform the colour of the surface by a visual point of view. 


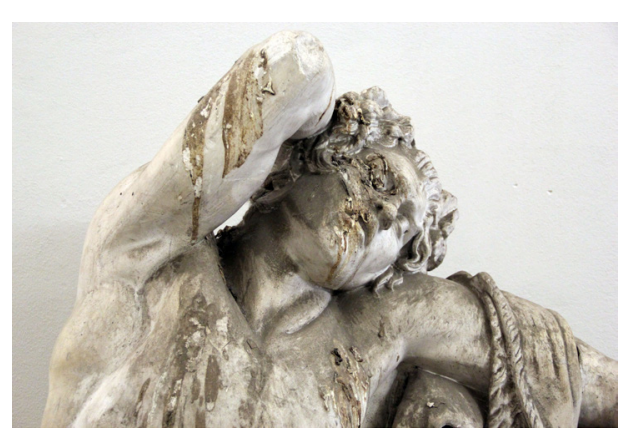

Fig. 24. Dry cleaning.

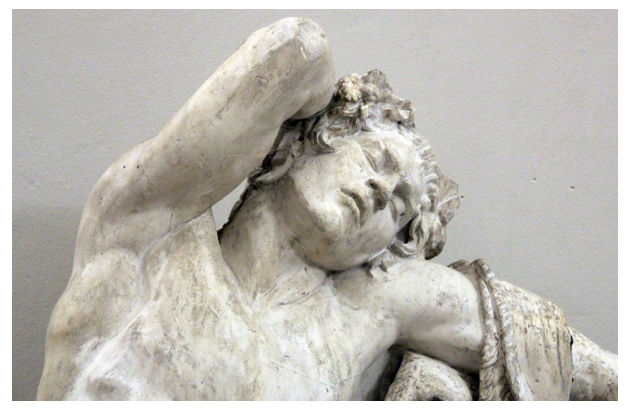

Fig. 25. Gel cleaning.

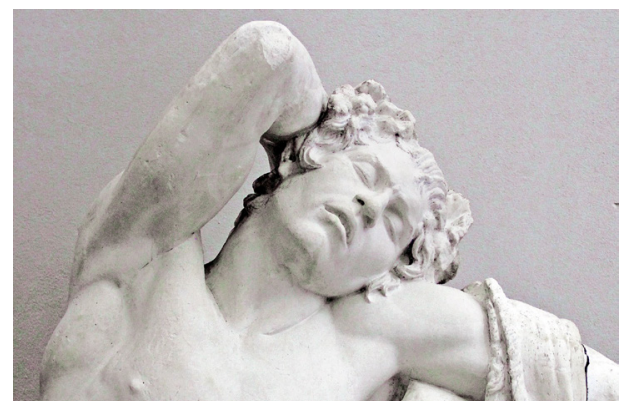

Fig. 26. Laser cleaning.
On the trunk of the Flora, using a fluence of 1.1 and of $1.7 \mathrm{~J} / \mathrm{cm}^{2}$, was the only possibility to obtain the appropriate cleaning level, not achievable with any other cleaning method. In fact, the presence of mortar patches on the side and the back of the trunk damaged heavily the sculpture; the laser cleaning system proved an extreme ability to remove unwanted materials. Through a careful calibration of the laser cleaning system, it was possible to reveal the subtle chromatic variations and the chiaroscuro effects, enhancing the legibility of the plaster cast surface.

The repetition rate changed importantly as to the different plaster casts, ranging from 7 to $18 \mathrm{~Hz}$; in fact, it was used as a valid tool to face the uneven level of deposits on the various surfaces and to obtain the correct restitution of the surface brightness.

All the values of the fluence quoted in the text are shown together with the correspondence with plaster areas in the following table (Tab. 1).

A very important aspect to stress is the crucial importance of safety, not only for the work of art but, in this special case for the students, for the workers and the public. All the students were trained specifically in order to use the laser in safe conditions. They have employed Individual Protection Devices during the restoration phases; they also

Table 1. Synoptic overview of used fluences $\left[\mathrm{J} / \mathrm{cm}^{2}\right]$

\begin{tabular}{|c|c|c|c|c|}
\hline \multirow{2}{*}{ Velletri Pallas } & Carnation & Dress & Basement & Base Low Rilief \\
\hline & $0.5 \rightarrow 1.1$ & $1 \rightarrow 1.4$ & 1.7 & $0.7 \rightarrow 1.0$ \\
\hline \multirow{2}{*}{ Flora Farnese } & Carnation & Dress & Basement & Tree Trunk \\
\hline & $0.5 \rightarrow 1.0$ & $0.9 \rightarrow 1.4$ & 1.7 & $1.1 \rightarrow 1.7$ \\
\hline \multirow{4}{*}{ Barberini Faun } & Carnation & Base & & \\
\hline & $0.7 \rightarrow 1.5$ & \multirow{3}{*}{$1.0 \rightarrow 1.7$} & & \\
\hline & Left Leg & & & \\
\hline & $1.0 \rightarrow 1.7$ AND 3 & & & \\
\hline
\end{tabular}


underwent a medical examination before and after the project. The importance of the detailed work plan is crucial when working in a crowded hallway: in fact, students and visitors frequently pass the hallway and we were obliged to set-up the site with strict laser safety barriers. The conservation site is under the supervision of the Ministry of Culture, which is located on the top floor of the Brera building; inspectors of the Ministry had a close supervision of the entire conservation process.

\section{Conclusion}

The Conservation School of Brera Academy is in charge of the maintenance and conservation of its own Cultural Heritage. The three case studies here presented were a pilot project for future works, taking into account the overall difficulties in cleaning gypsum based materials due to its solubility and low mechanical properties. Newberyite was highlighted in the near surface region as a new mineral formation, which possibly comes from guano; it is supposed to be related with a superficial grey layer, but further investigation is still needed. The laser cleaning technology was applied with success after preliminary treatments, with the aim to lower the grey layer already mentioned. The casts have been cleaned with THUNDER ART @ 532 nm, in the QS regime, ranging the fluence from 1.1 to 1.7 $\mathrm{J} / \mathrm{cm}^{2}$ and the repetition rate from 12 to 20 $\mathrm{Hz}$ in the average. The performance of laser cleaning treatments proved to be effective in removing the grey layer from the substrate.

\section{References}

[1] M. Anzani, L. Borgioli, A. Brunetto, A. Rabbolini, A. Sansonetti, J. Striova, "Sperimentazione di pulitura laser con intermediazione di gel di agar" in: APLAR 3 - Applicazioni LASER nel Restauro, Bari 18-19 june, 2010, Il prato 2011, pp. 45-58.

[2] S. Siano, J. Agresti, I. Cacciari, D. Ciofini, M. Mascalchi, I. Osticioli, A. A. Mencaglia, "Laser cleaning in conservation of stone, metal and painted articafts: state of the art and new insights on the use of the Nd:YAG lasers", 106 (2012) 419-446, DOI: 10.1007/ s00339-011-6690-8.

[3] A. Sansonetti, C. Colombo, M. Realini, M. Palazzo, M. De Marchi, "Laser cleaning of stucco's fragments from an early middle age bas-relief" in: Lasers in the Conservation of Artworks VII, Proceedings of International Conference Lacona VII Madrid, Spain, 17-21 Sep. 2007, Marta Castillejo, Pablo Moreno, Mohamed Oujja, Roxana Radvan, Javier Ruiz (Eds.), CRC Press 2008, pp. 243-248.

[4] Z. Mesikova, P. Sulcova, M. Trojan, "Syntesis and characterization of Newberyte", J. of Thermal Analysis and Calorimetry, 88 (2007) 103-106.DOI: 10.1007/ s10973-006-8099-8.

[5] R.L. Frost, S.J. Palmer, R. Pogson, "Raman spectroscopy of newberyite $\mathrm{Mg}\left(\mathrm{PO}_{3} \mathrm{OH}\right) \cdot 3 \mathrm{H}_{2} \mathrm{O}$ - a cave mineral", Spectrochimica Acta Part A., 79 (2011). DOI: 10.1016/j.saa.2011.04.035.

[6] M. Hanhoun, L. Montastruc C. Azzaro-Pantel, B. Biscans, M. Freche, L. Pibouleau, “Temperature impact assessment on struvite solubility product: a thermodynamic modeling approach", Biochemical Engineering Journal, 167 (2011) 50-58, DOI: 10.1016/j.cej.2010.12.001.

[7] A.W. Taylor, A.W. Frazier, E.L. Gurney, J.P. Smith, "Solubility products of di-and trimagnesium phosphates and the dissociation of Magnesium phosphate solutions", Transactions Faraday Soc., $1963,59,1585-1589$.

[8] A. Freund, G. Eggert, H. Kutzker, B. Barbier, "On the occurrence of magnesium phosphates on ivory", Studies in Conservation, 47 (2002) 155-160. 